\title{
A Critical Review of Time-frequency Distribution Analysis for Detection and Classification of Harmonic Signal in Power Distribution System
}

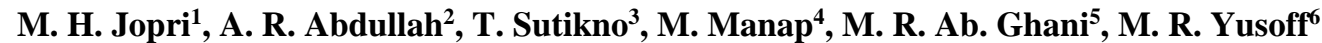 \\ ${ }^{1,4,6}$ Center for Robotics and Industrial Automation (CeRIA), Faculty of Engineering Technology, Universiti Teknikal \\ Malaysia Melaka, Malaysia \\ ${ }^{2,5}$ CeRIA, Faculty of Electrical Engineering, Universiti Teknikal Malaysia Melaka, Malaysia \\ ${ }^{3}$ Department of Electrical Engineering, Universitas Ahmad Dahlan (UAD), Indonesia
}

\begin{tabular}{|c|c|}
\hline Article Info & ABSTRACT \\
\hline $\begin{array}{l}\text { Keyword: } \\
\text { Classification } \\
\text { Detection } \\
\text { Gabor transform } \\
\text { Harmonic } \\
\text { Spectrogram } \\
\text { S-transform } \\
\text { Time-frequency distribution }\end{array}$ & $\begin{array}{l}\text { This paper presents a critical review of time-frequency distributions (TFDs) } \\
\text { analysis for detection and classification of harmonic signal. } 100 \text { unique } \\
\text { harmonic signals comprise of numerous characteristic are detected and } \\
\text { classified by using spectrogram, Gabor transform and S-transform. The rule- } \\
\text { based classifier and the threshold settings of the analysis are according to the } \\
\text { IEEE Standard } 11592009 \text {. The best TFD for harmonic signals detection and } \\
\text { classification is selected through performance analysis with regards to the } \\
\text { accuracy, computational complexity and memory size that been used during } \\
\text { the analysis. }\end{array}$ \\
\hline \multicolumn{2}{|l|}{ Corresponding Author: } \\
\hline \multicolumn{2}{|c|}{$\begin{array}{l}\text { M. H. Jopri, } \\
\text { Advanced Digital Signal Processing Group, } \\
\text { Center for Robotics and Industrial Automation (CeRIA), } \\
\text { Faculty of Electrical Engineering, } \\
\text { Universiti Teknikal Malaysia Melaka (UTeM), Hang Tuah Jaya, } \\
\text { 76100 Durian Tunggal, Melaka, Malaysia. } \\
\text { Email: hatta@utem.edu.my }\end{array}$} \\
\hline
\end{tabular}

\section{INTRODUCTION}

The power quality (PQ) term originates from the idea that the AC voltage supplied to the domestic and industrial equipment must be unpolluted sinusoidal and its frequency and magnitude as must be in the range of IEEE and IEC standards. Nowadays, one of the main issue of PQ is harmonic pollution, this is due to the use of different power electronics equipment and nonlinear loads [1], [2]. A harmonic pollution monitoring in the distribution system is vital for the study of the root causes, harmonic level and mitigation [3]-[5]. This harmonic pollution can decline the PQ, it additionally can increase the power losses and lead to the malfunction of equipment and measurement [6], [7].

A comprehensive research is necessary for producing an accurate, fast and reliable method for the harmonic signal detection and classification [8], [9]. Numerous methods are proposed for detection and classification of a harmonic signal, as straightforward and fast such as Fast Fourier Transform (FFT) [10]. FFT is effectively employed on stationary signals [11], [12]. Yet, FFT is not an appropriate method for nonstationary signal analysis and contributes time information loss throughout the frequency domain conversion [13], [14]. To deal with non-stationary signal, short-time Fourier transform (STFT) is introduced [14], [15]. 
Nevertheless, STFT is not proficient to detect the dynamic signal property because the window width fixed to affect the frequency-time resolution [6], [8], [16]. Whereas, the time-frequency resolution depends upon the size of the window [17], [5].

The constraint of STFT is resolved by utilizing Gabor transform (GT) and GT has the feature of extraction tool, due to the optimality concerning the time-frequency uncertainty characteristic [18]. As suggested by GT, the functions are well-defined as Gaussian envelope modulated by complex sinusoids with a fixed envelope for all frequencies [19]-[21]. However, the result shows that the method requires high computation complexity compared to the STFT due to the use of discrete Fourier transform (DFT) [10]. In order to overcome STFT and GT limitation, the wavelet transform (WT) is proposed [22]. WT can extract the significant information from non-stationary and it can distinguish the signal characteristics [6], [18], [23]. The major drawback of WT are the accuracy thoroughly relies on the chosen mother wavelet, sensitive to the level of noise and high computation complexity [18], [24], [25]. Subsequently, a combination of STFT and WT known as S-transform (ST) is presented due to mitigate the WT problem [6], [26], [27]. Furthermore, the ST is a reliable technique to characterize the harmonic parameters [26], [28], [22]. The ST also offers an extraordinary multiresolution analysis while characterizing the harmonic components [9], [18], [16], [22]. Based on above discussion, an evaluation and a critical review of TFDs for harmonic signal detection and classification are crucial and need to be done.

The main concern of this paper is to evaluate and review the best TFDs in harmonic signal detection and classification technique. The assessment of the harmonic signal analysis is using the TFDs such as spectrogram, GT and ST are actualized in time-frequency domain [29], [30]. The performance of each TFD is compared and validated with regards to accuracy, computational complexity and the used memory size during the analysis. The performance of these TFDs are validated by detecting and classifying the 100 unique signals with numerous characteristics of harmonic signal accordingly to the IEEE Std. 1159-2009. The best TFD is chosen by determining the most accurate method, used low memory size and additionally low computational complexity.

\section{HARMONIC SIGNAL ANALYSIS}

There are four primary phases in the harmonic signal detection and classification analysis as shown in Figure 1. The 1st phase is the signal normalization and representation of time-frequency representation (TFR). Meanwhile, the 2nd phase is the estimation of fundamental signals parameters. Moreover, the 3rd phase is the signal characteristics identification and finally, the 4th phase is the harmonic signal classification. The harmonic signal is standardized where the voltage magnitude is changed into the per-unit system. Meanwhile, via TFDs, the outcome of the analysis is presented in the time-frequency domain.

The parameters comprise of the RMS fundamental voltage, total waveform distortion, instantaneous of RMS voltage, total nonharmonic distortion and total harmonic distortion are calculated. Lastly, according to the IEEE Std. 1159-2009, this information is utilized as the rule-based classifier input due to classify the harmonic signals.

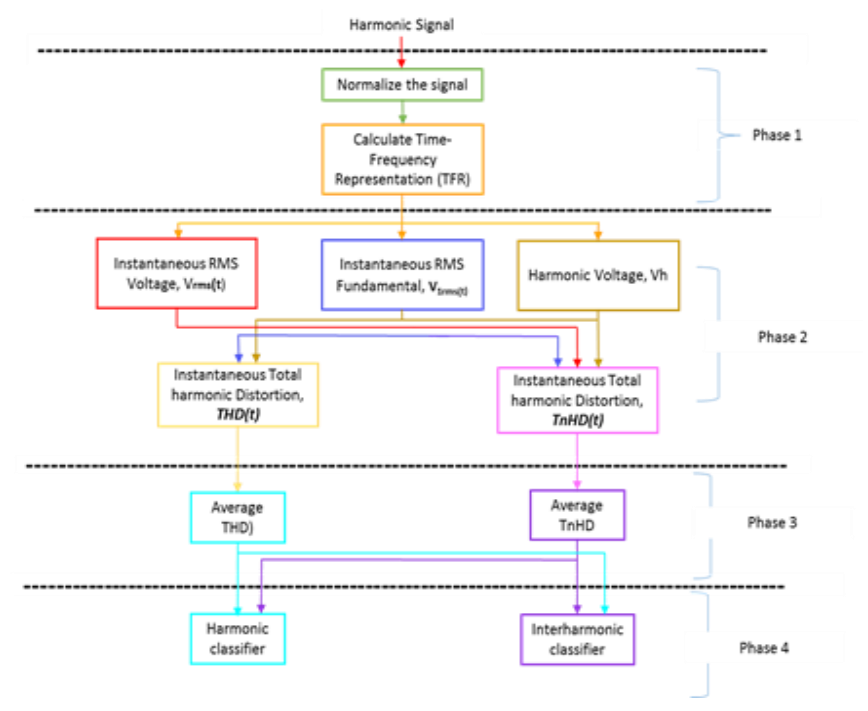

Figure 1. Flow chart of harmonic signal detection and classification 


\section{HARMONIC SIGNALS MODELING}

Due to model the signals for analysis, a few parameters for each unique signal are proposed and permitted to be altered according to the IEEE Std. 1159-2009. The signal model can be written as a complex exponential signal and well-defined as [31],

$$
x_{w d}(t)=e^{j 2 \pi f_{0} t}+A e^{j 2 \pi f_{1} t}
$$

Whereby, $f_{o}$ is the fundamental signal frequency and $f_{l}$ is the harmonic or interharmonic frequency and $\mathrm{t}$ is the time, $f_{l}=250 \mathrm{~Hz}, \mathrm{~A}=0.25$ for harmonic and $f_{l}=275 \mathrm{~Hz}, \mathrm{~A}=0.25$ for interharmonic.

\section{THE TIME-FREQUENCY DISTRIBUTIONS}

Time-frequency distributions (TFDs) are excellent methods that presented a signal in timefrequency representation and recognized as time-frequency representation (TFR). In the subsequent sections, the TFDs consist of the spectrogram, GT and ST are explained.

\subsection{Spectrogram}

The spectrogram is a method to represents a signal energy distribution in jointly time and frequency [32]. It is well-defined as, in this research, the Hanning window is carefully chosen as its lower peak side lope has a feature of narrow effect on the frequency components. For this research, the length of the window is 512 and the frequency and time resolution for spectrogram is fixed for all frequencies.

$$
P_{x}(t, f)=\left|\int_{-\infty}^{\infty} x(\tau) w(\tau-t) e^{-j 2 \pi f \tau} d \tau\right|^{2}
$$

\subsection{Gabor Transform}

The descriptor of signal's local property of Gabor transform (GT) is obtained from a set of functions that are condensed in frequency and time domains [25]. The GT is well expressed by, in GT, Hanning window is used as well as a spectrogram, however dissimilar of window length. The resolution of frequency and time for GT is always same for all frequencies.

$$
C(n, k)=\int_{-\infty}^{\infty} x(\tau) h^{*}(n, k) d \tau
$$

\subsection{S-transform}

S-transform (ST) is a hybrid of short time Fourier transform (STFT) and wavelet transform and used as a time-frequency spectral localization method [17]. ST utilizes a scalable of the Gaussian window and the resolution of frequency based on the simultaneous localization of the real and imaginary spectra [5]. The ST is well written as,

$$
\begin{aligned}
& S T(\tau, f)=\int_{-\infty}^{\infty} h(t) \frac{|f|}{\sqrt{2 \pi}} e^{\frac{-(\tau-t)^{2} f^{2}}{2}} e^{-j 2 \pi f t} d t \\
& g(t)=\frac{1}{\sigma \sqrt{2 \pi}} e^{\frac{-t^{2}}{2 \sigma^{2}}} \\
& \sigma(f)=\frac{1}{|f|}
\end{aligned}
$$

Whereby $h(t)$ is the signal, $g(t)$ is the scalable Gaussian window and $\sigma(f)$ is a control parameter for the Gaussian window. ST offers superior frequency resolution for lower frequency. Meanwhile, for higher frequency, ST delivers good time resolution. The extraction of frequency components is achieved by utilizing wide window (low frequency) and narrow window (high frequency) due to compose high frequency 
components [32]. In this research, spectrogram and GT with the utilization of Hanning window are used to calculate the time and frequency. Meanwhile, the scalable Gaussian window is used for ST method.

\section{SIGNAL PARAMETERS}

Harmonic signals parameters are estimated from the TFR and the signal parameters consist of instantaneous RMS voltage and RMS fundamental voltage, instantaneous total waveform distortion (TWD), instantaneous total harmonic distortion (THD) and instantaneous total interharmonic distortion (TnHD).

\subsection{Instantaneous RMS Voltage}

Root-mean square (RMS) voltage, $V_{r m s}$ is defined as [32],

$$
V_{r m s}(t)=\sqrt{\int_{0}^{f_{s}} P_{x}(t, f) d f}
$$

Whereby $\operatorname{Px}(t, f)$ is the TFR signal and $f s$ is sampling frequency.

\subsection{Instantaneous RMS Fundamental Voltage}

From the TFR, the instantaneous RMS fundamental voltage, $V_{\text {Irms }}(t)$, can be calculated using [31],

$$
\begin{gathered}
V_{1 r m s}(t)=\sqrt{2 \int_{f_{l o}}^{f_{h i}} P_{x}(t, f) d f} \\
f_{h i}=f_{0}+25 \mathrm{~Hz} \\
f_{l o}=f_{0}-25 \mathrm{HZ}
\end{gathered}
$$

Whereby $P_{x}(t, f)$ is the TFR signal, $f_{o}$ is the fundamental frequency.

\subsection{Instantaneous Total Waveform Distortion}

The total waveform distortion, TWD is well-defined as the relative signal energy existing at a nonfundamental frequency and expressed as [31],

$$
T W D(t)=\frac{\sqrt{V_{r m s}(t)^{2}-V_{1 r m s}(t)^{2}}}{V_{1 r m s}(t)}
$$

\subsection{Instantaneous Total Harmonic Distortion}

Total harmonic distortion, $T H D$, is utilized due to measure the harmonic content in a waveform and formulated as [31],

$$
T H D(t)=\frac{\sqrt{\sum_{h=2}^{H} V_{h, r m s}(t)^{2}}}{V_{1 r m s}(t)}
$$

\subsection{Instantaneous Total Nonharmonic Distortion} using [31],

A signal also comprises interharmonic components and the interharmonic level can be calculated

$$
\operatorname{Tn} H D(t)=\frac{\sqrt{V_{r m s}(t)^{2}-\sum_{h=0}^{H} V_{h, r m s}(t)^{2}}}{V_{1 r m s}(t)}
$$




\section{SIGNAL CHARACTERISTIC}

The characterization of signals is obtained from the calculated signal parameters. Average of total harmonic distortion, $T H D_{\text {ave }}$ and total nonharmonic distortion, $T n H D_{\text {ave }}$ can be calculated from instantaneous total harmonic distortion, $T H D(t)$ and instantaneous total nonharmonic distortion, $T n H D(t)$, respectively. These characteristics can be expressed as [31],

$$
\begin{aligned}
& V_{r m s, a v e}=\frac{1}{T} \int_{0}^{T} V_{r m s}(t) d t \\
& T H D_{\text {ave }}=\frac{1}{T} \int_{0}^{T} T H D(t) d t \\
& T n H D_{\text {ave }}=\frac{1}{T} \int_{0}^{T} \operatorname{TnHD}(t) d t
\end{aligned}
$$

\section{SIGNAL CLASSIFICATION}

A deterministic classification method which is the rule-based classifier extensively employed in the practical application. This method is easy to be implemented and its performance is much reliant on the threshold settings and expert rules. The flow chart in Figure 2 describes a rule-based classifier for the harmonic signals. Furthermore, the threshold settings are set according to IEEE Std. 1159-2009.

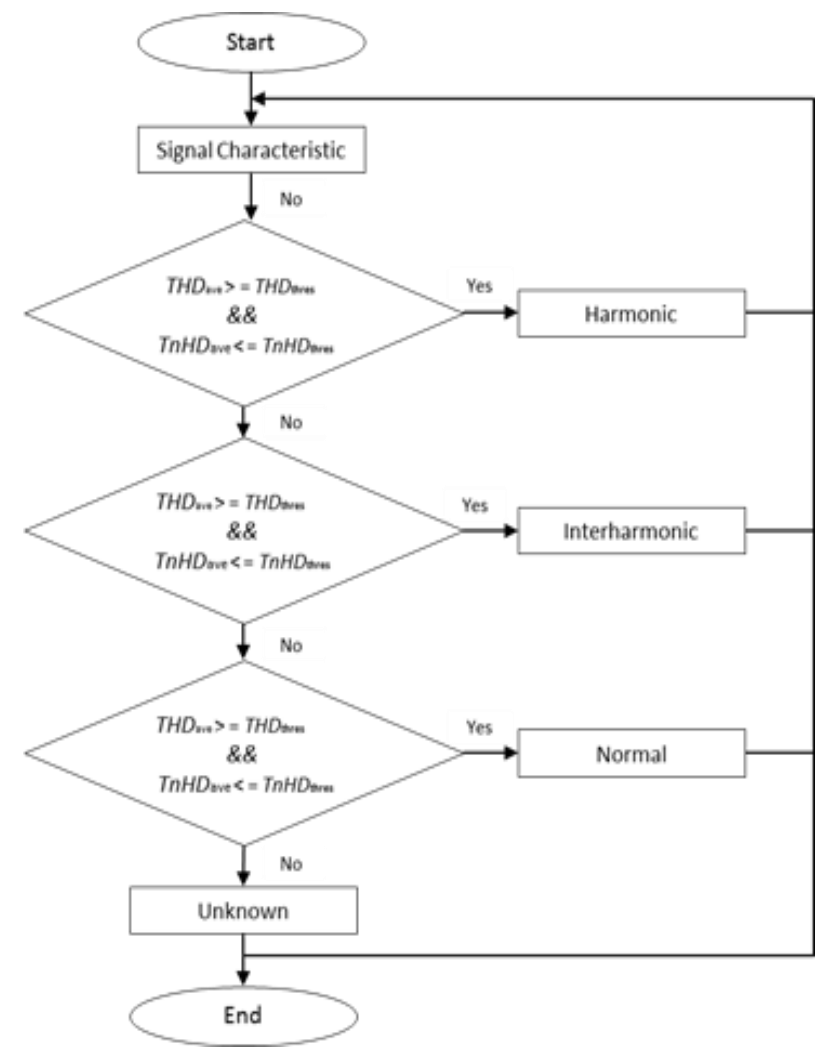

Figure 2. The rule-based classifier flow chart for harmonic signals

\section{PERFORMANCE MEASUREMENTS OF TIME-FREQUENCY DISTRIBUTIONS}

The performance and viability of proposed method depend on the accuracy of this technique and the evaluation of accuracy can be done as follows. 


\subsection{The Analysis Accuracy}

The analysis accuracy is calculated through the signal characteristics measurement accuracy. To measure the measurement accuracy, the mean absolute percentage error (MAPE) is employed as an accuracy index. The lower the MAPE, the better the performance of the signal characteristics measurement [32]. It can be written as,

$$
M A P E=\frac{1}{N} \sum_{n=1}^{N}\left|\frac{x_{i}(n)-x_{m}(n)}{x_{i}(n)}\right| x 100 \%
$$

Whereby $x_{i}(n)$ is an actual value, $x_{m}(n)$ is measured value and $N$ is the data number. The smaller value of the MAPE, the better the accuracy is.

\subsection{The Computational Complexity of the Analysis}

The computational complexity of TFDs to represent the TFR of signals reliant on the parameters setting of each TFD. The spectrogram and ST both used fast Fourier transform (FFT) that deals fast computation. Meanwhile, GT executes discrete Fourier transform (DFT) and has more computational complexity compare to FFT [18]. The computational complexity index can be calculated as follows,

$$
\begin{aligned}
& C r_{\text {spectrogram }}=N-N_{w}\left(N_{w} \log _{2}\left(N_{w}\right)\right) \\
& C r_{\text {Gabor }}=N-N_{w}\left(N_{w}^{2}\right) \\
& C r_{S T}=N-N_{w}\left(N_{w}+N_{w} \log _{2}\left(N_{w}\right)\right)
\end{aligned}
$$

\subsection{The Memory Size of the Analysis}

The signal length number and TFD parameters setting influence the size of memory used for TFR [18]. The memory is expressed as,

$$
\text { Memory }_{\text {LinearTFD }}=\frac{N_{w}\left(N-N_{w}\right)}{N_{s}}
$$

\section{RESULTS AND ANALYSIS}

This section discuss the results of harmonic signals detection and classification analysis by using TFDs and the best TFD is chosen based on the accuracy, computational complexity and memory size during the TFDs analysis. This section discuss the results of harmonic signals detection and classification analysis by using TFDs and the best TFD is chosen based on the accuracy, computational complexity and memory size during the TFDs analysis.

\subsection{Harmonic Signal Analysis by Using Spectrogram}

Figure 3(a) and 3(b) depict harmonic signal in the time domain and the TFRs using spectrogram. The TFRs show the signal parameters comprise of the fundamental frequency at $50 \mathrm{~Hz}$ and the 7 th harmonic component at $350 \mathrm{~Hz}$, respectively. Furthermore, Figure 3(c) shows that the harmonic voltage has contributed to the rise of the RMS voltage from 1.0 to $1.17 \mathrm{pu}$. However, the RMS fundamental voltage still remains at $1.0 \mathrm{pu}$. Besides that, the TWD and THD of the signals are $60 \%$ and zero TnHD are calculated and presented well in Figure 3(d). Hence, from the analysis show that there is no interharmonic signal is exist in the signal.

The existence of interharmonic signal is analyzed with spectrogram and its TFR is demonstrates in Figure 4(a) and 4(b), separately. As demonstrates in Figure 4(b), the signal consists of fundamental frequency at $50 \mathrm{~Hz}$ and the interharmonic frequency at $375 \mathrm{~Hz}$, respectively. Figure 4(c) shows that the existence of interharmonic voltage has increased the RMS voltage from 1.0 to $1.17 \mathrm{pu}$. The analysis also results the TWD and $T n H D$ are $60 \%$ and as depicts in Figure $4(\mathrm{~d})$, the $T H D$ is zero percent. Therefore, the results of the analysis show only fundamental and interharmonic signal exist in the signal. 


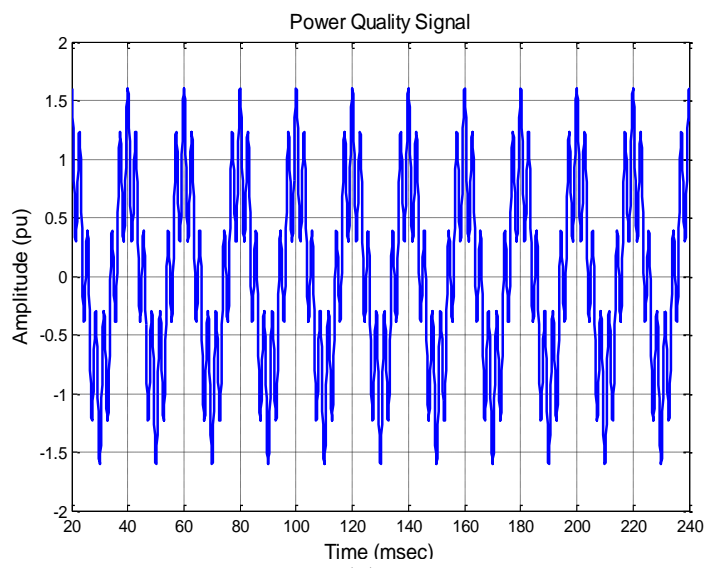

(a)
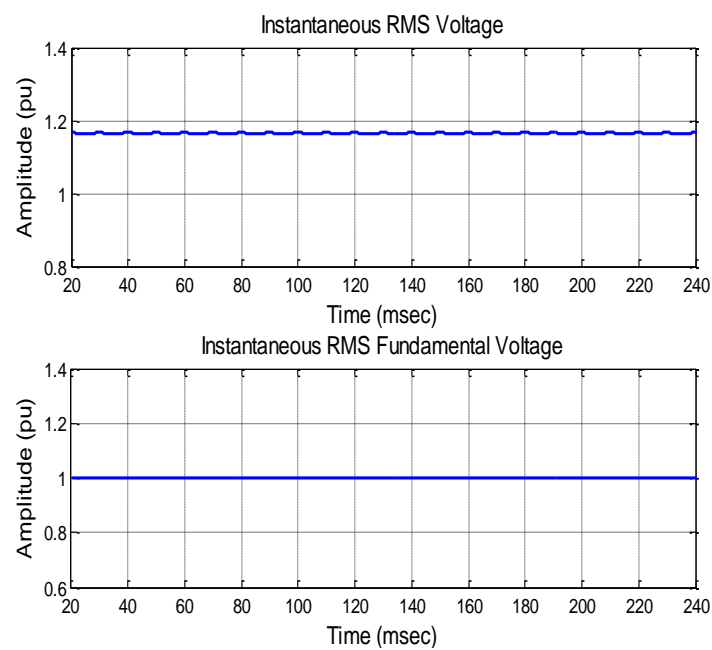

(c)

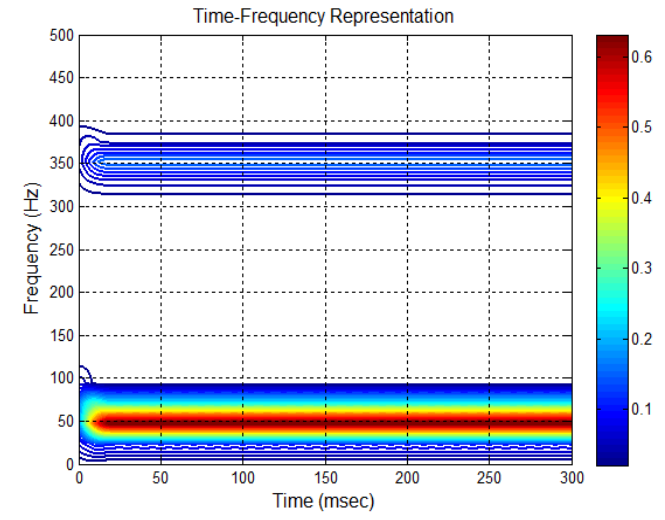

(b)
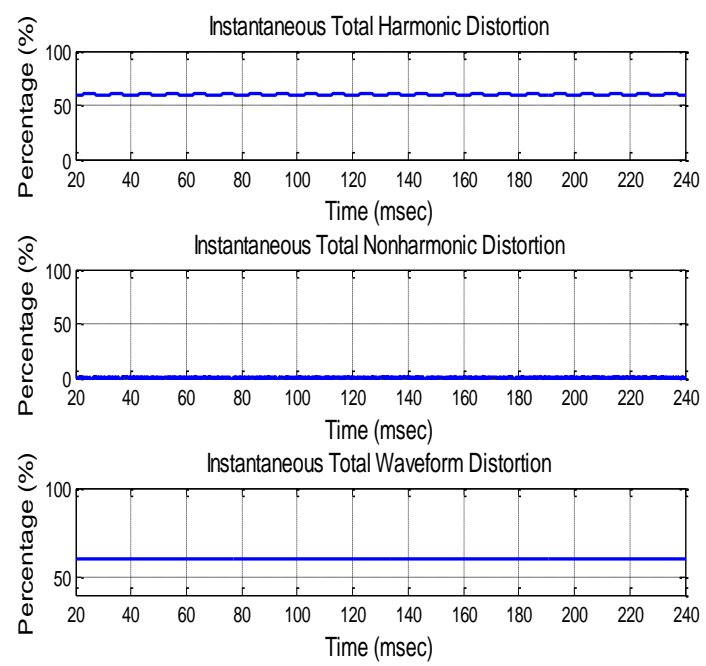

(d)

Figure 3. (a) Harmonic signal in time domain, (b) Harmonic signal in TFR, (c) Instantaneous RMS voltage and RMS fundamental voltage, (d) Instantaneous total harmonic distortion, total nonharmonic distortion and total waveform distortion.

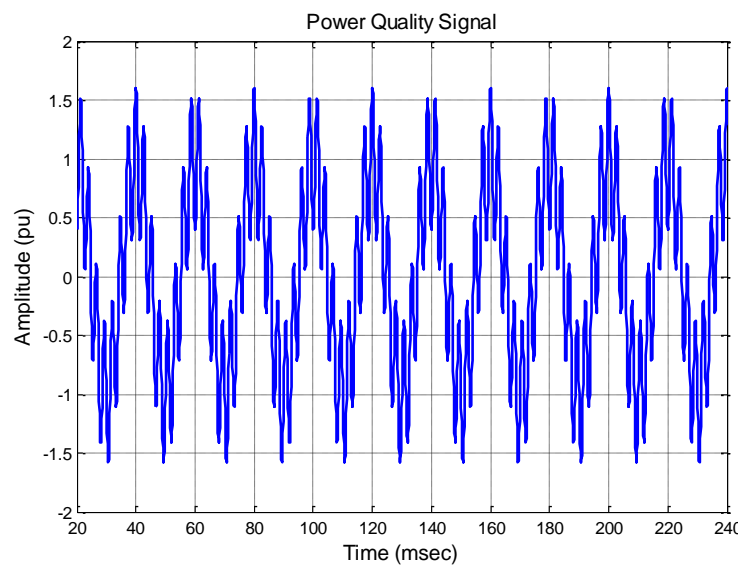

(a)

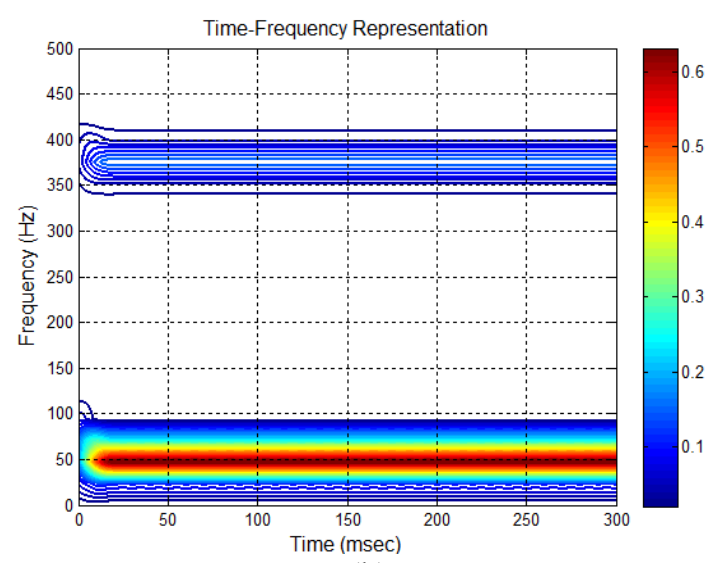

(b)

Figure 4. (a) Interharmonic signal in time domain, (b) Harmonic signal in TFR, (c) Instantaneous RMS voltage and RMS fundamental voltage, (d) Instantaneous total harmonic distortion, total nonharmonic distortion and total waveform distortion. 


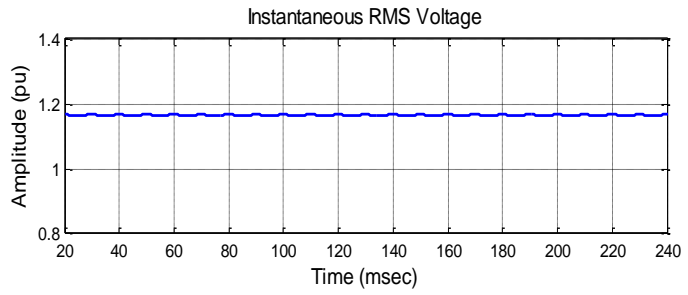

Instantaneous RMS Fundamental Voltage

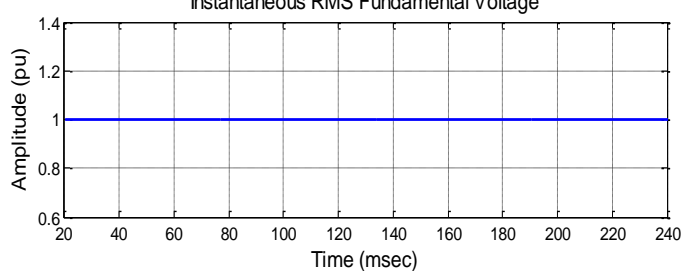

(c)
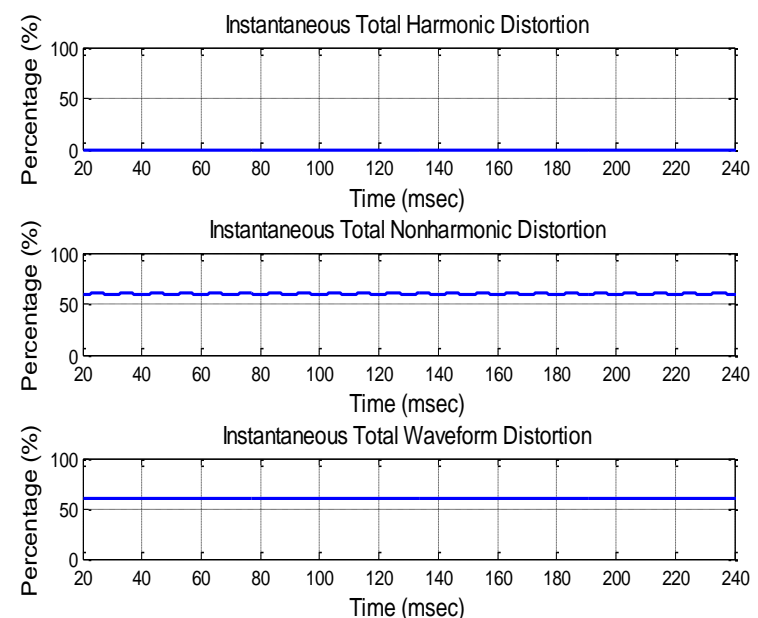

(d)

Figure 4. (a) Interharmonic signal in time domain, (b) Harmonic signal in TFR, (c) Instantaneous RMS voltage and RMS fundamental voltage, (d) Instantaneous total harmonic distortion, total nonharmonic distortion and total waveform distortion.

\subsection{Signal Analysis Using Gabor Transform}

Figure 5(a) and 5(b) present harmonic signal in time domain and the TFR by using GT. From the TFR, is show that the signal contains fundamental frequency at $50 \mathrm{~Hz}$ and the 7 th harmonic component at $350 \mathrm{~Hz}$. In the meantime, Figure 5(c) shows that the existence of harmonic voltage has increased the RMS voltage from 1.0 to $1.17 \mathrm{pu}$. The analysis outcome in Figure 5(d) shows that the TWD and THD of the signal at a value $60 \%$ and the TnHD is zero percent as figured in Figure 5(d). Thus, it is clearly shown that no interharmonic component exists in the signal.

Figure 6(a) and 6(b) show the analysis outcome of the signal with interharmonic component and the TFR using GT. From the TFR, it shows that only the fundamental frequency at $50 \mathrm{~Hz}$ and the interharmonic component at $375 \mathrm{~Hz}$ are exist in the signal. Meanwhile, as shown in Figure 6(c), the existence of interharmonic voltage has increased the RMS voltage from is 1.0 to $1.17 \mathrm{pu}$. In addition, from Figure 6(d), the analysis also presents the value of TWD and TnHD is $60 \%$ and zero percent for THD. Thus, from the analysis clearly show that only fundamental and interharmonic components exist in the signal.

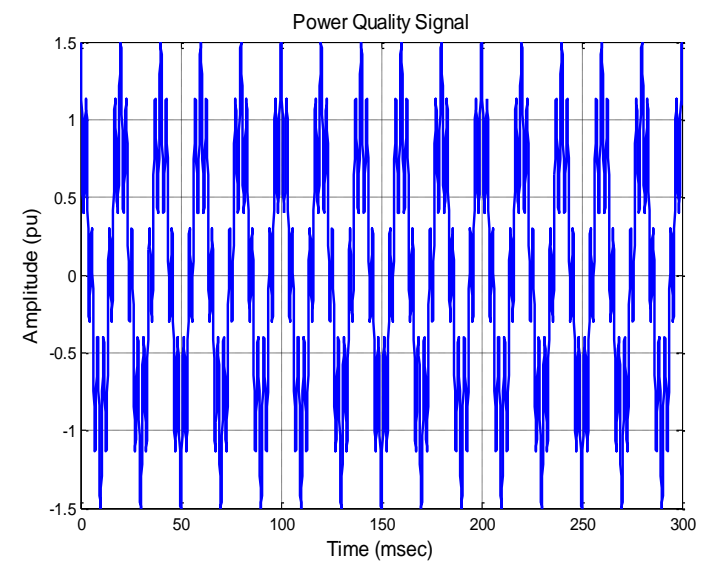

(a)

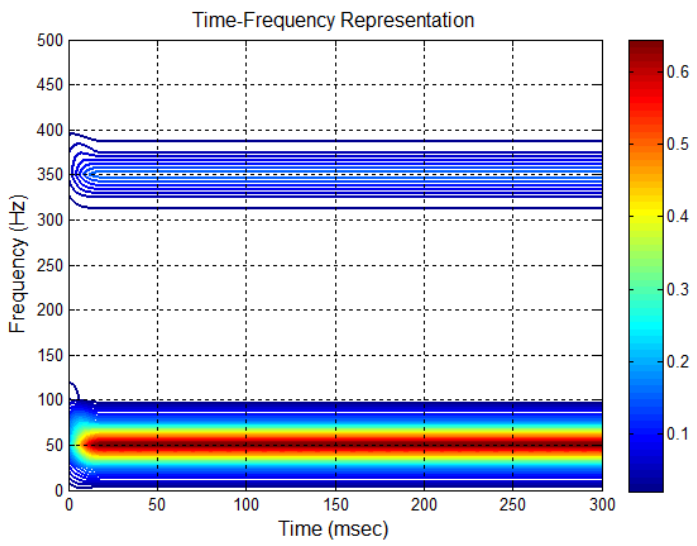

(b)

Figure 5. (a) Harmonic signal in time domain, (b) Harmonic signal in TFR, (c) Instantaneous RMS voltage and RMS fundamental voltage, (d) Instantaneous total harmonic distortion, total nonharmonic distortion and total waveform distortion 

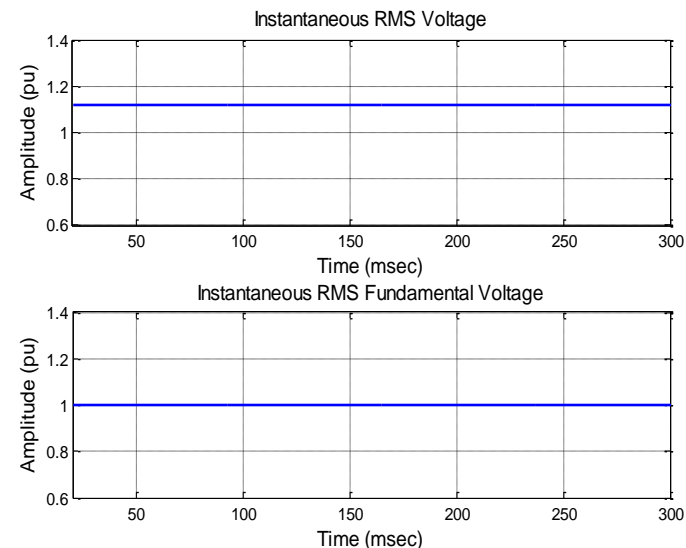

(c)
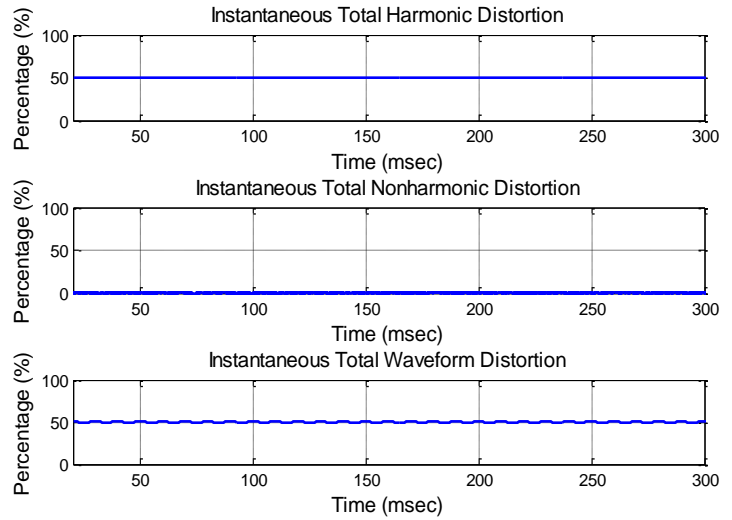

(d)

Figure 5. (a) Harmonic signal in time domain, (b) Harmonic signal in TFR, (c) Instantaneous RMS voltage and RMS fundamental voltage, (d) Instantaneous total harmonic distortion, total nonharmonic distortion and total waveform distortion

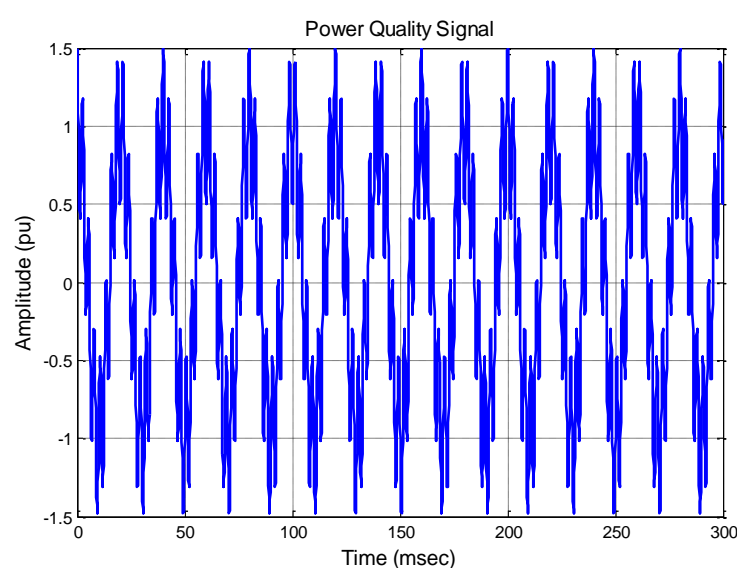

(a)
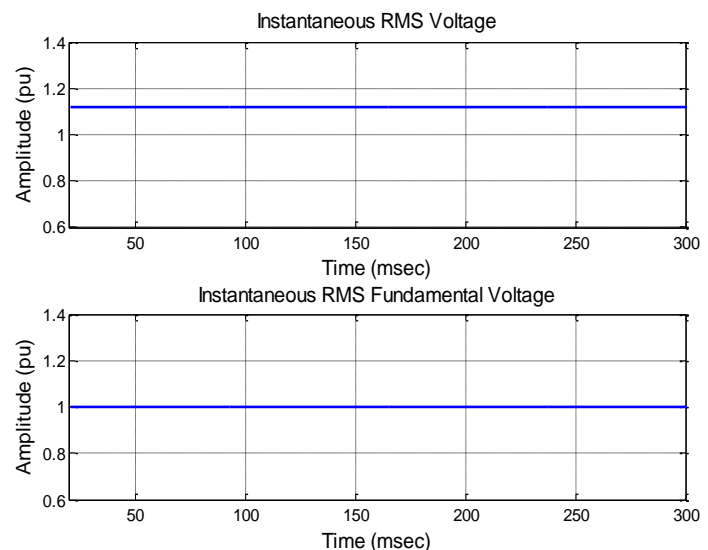

(c)

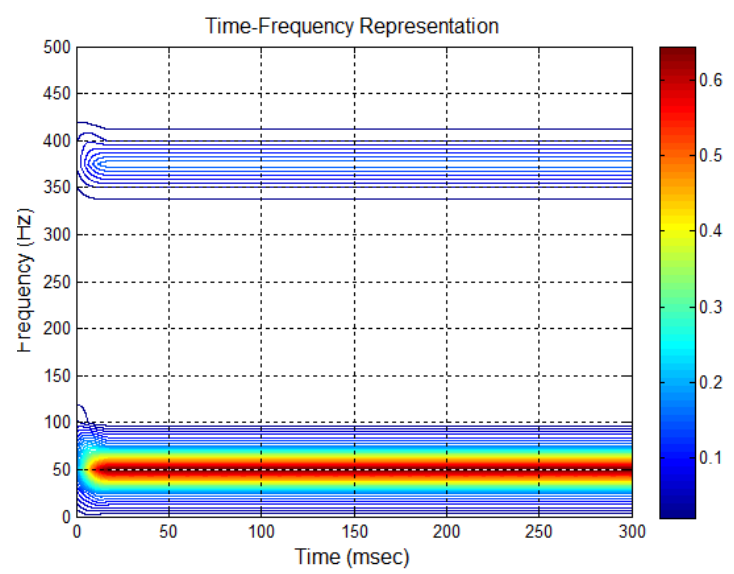

(b)
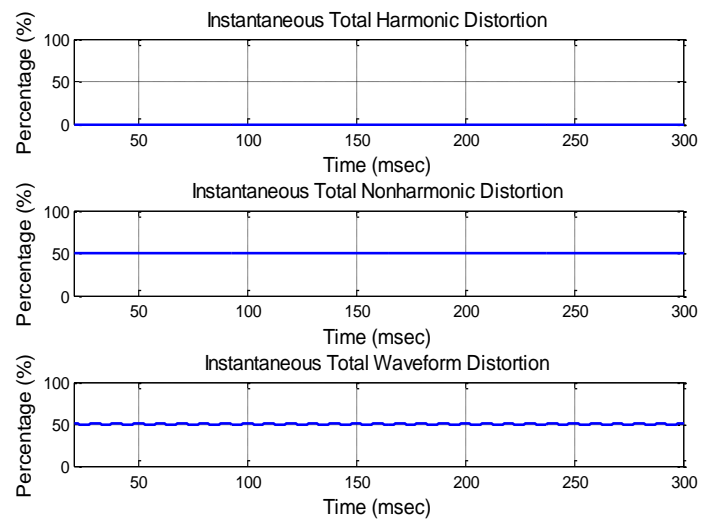

(d)

Figure 6. (a) Interharmonic signal in time domain, (b) Harmonic signal in TFR, (c) Instantaneous RMS voltage and RMS fundamental voltage, (d) Instantaneous total harmonic distortion, total nonharmonic distortion and total waveform distortion 


\subsection{Signal Analysis Using S-transform}

Figure 7(a) and 7(b) present harmonic signal in time domain and the TFR by using ST. From the TFR, it is clearly figured that the signal comprises the fundamental frequency at $50 \mathrm{~Hz}$ and the 7 th harmonic component at $350 \mathrm{~Hz}$. In the meantime, Figure 4(c) shows that the existence of harmonic component has increased the RMS voltage from 1.0 to $1.1 \mathrm{pu}$. In addition, Figure 4(d) demonstrates the magnitude of TWD and $T H D$ is $10 \%$ and zero percent for the TnHD. Hence, from the analysis, it is plainly shown that no interharmonic component exists in the signal.

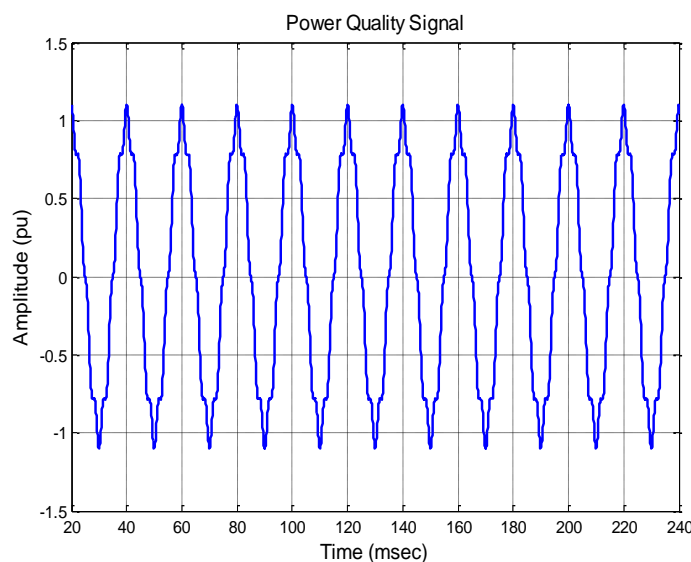

(a)
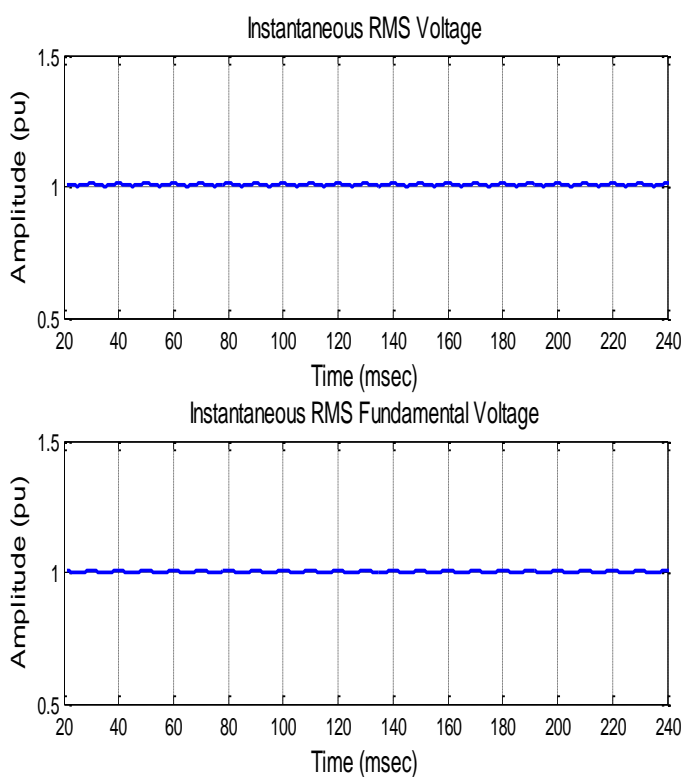

(c)

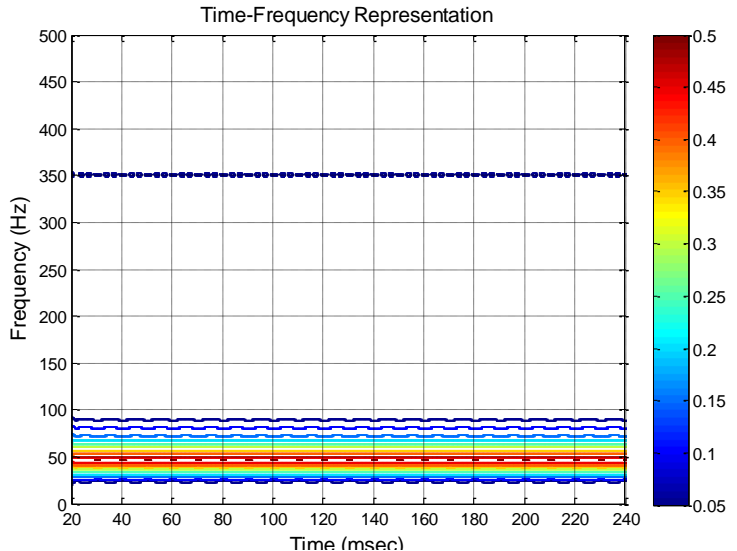

(b)
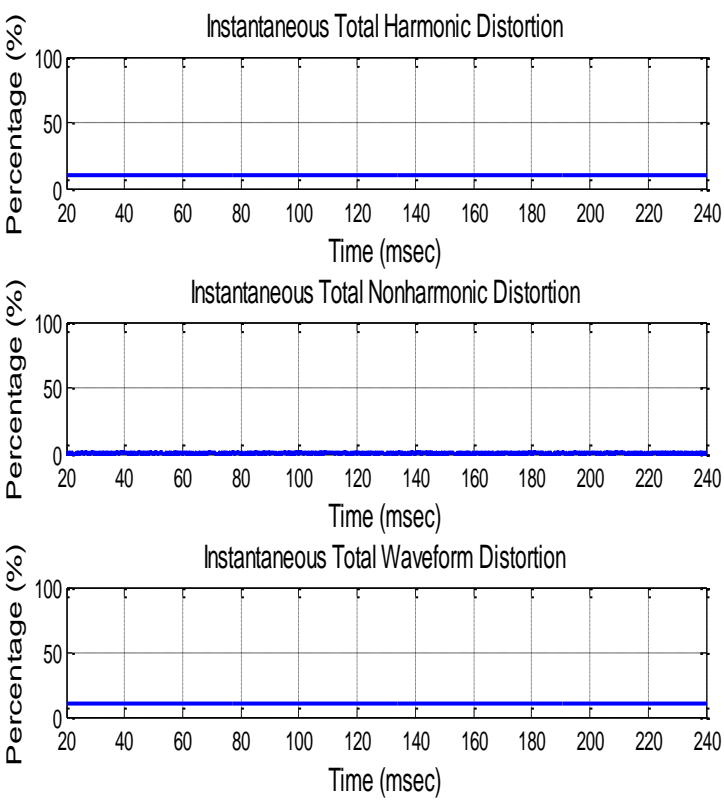

(d)

Figure 7. (a) Harmonic signal in time domain, (b) Harmonic signal in TFR, (c) Instantaneous RMS voltage and RMS fundamental voltage, (d) Instantaneous total harmonic distortion, total nonharmonic distortion and total waveform distortion

Figure 8(a) and 8(b) present the interharmonic signal and the TFR by using ST, respectively. The signal has a fundamental component at $50 \mathrm{~Hz}$ and interharmonic component at $375 \mathrm{~Hz}$. Figure 8(c) shows that the interharmonic voltage contributes to the rise of RMS from 1.0 to $1.1 \mathrm{pu}$. In addition, the signal analysis presents the magnitude of $T W D$ and TnHD with a value of $10 \%$ and zero percent for the $T H D$ as shown in Figure $8(\mathrm{~d})$. Thus, the analysis clearly shows that only the fundamental and interharmonic components exist in the signal. 


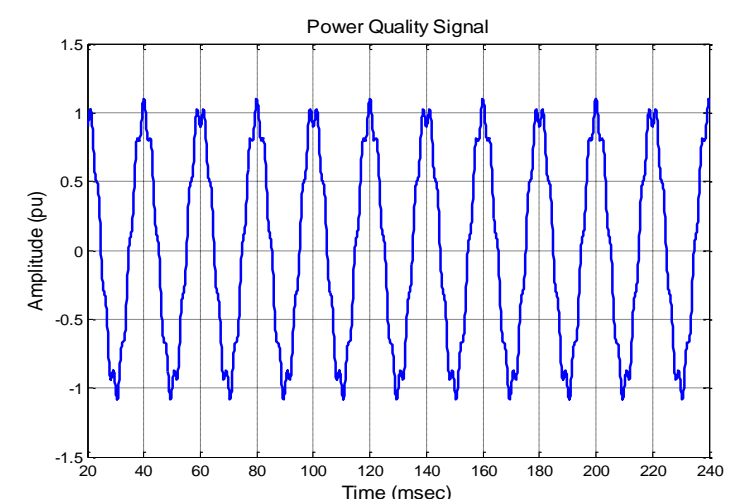

(a)
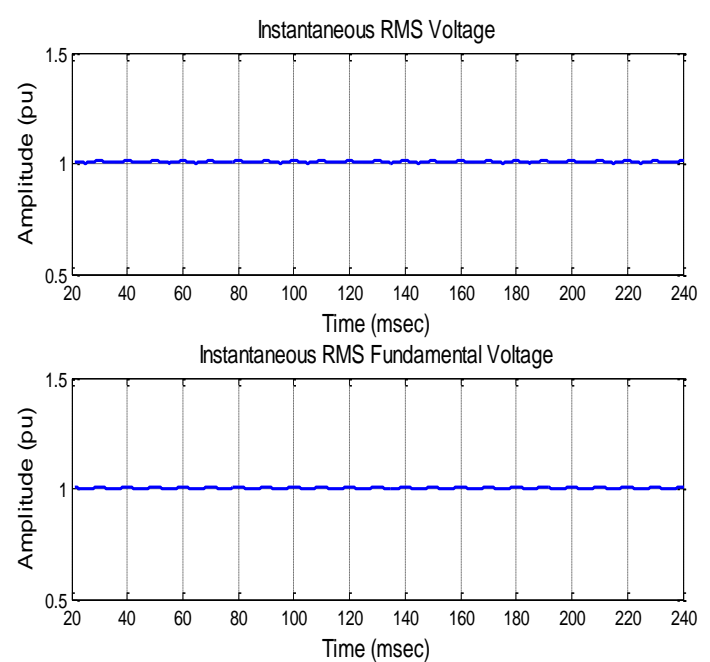

(c)

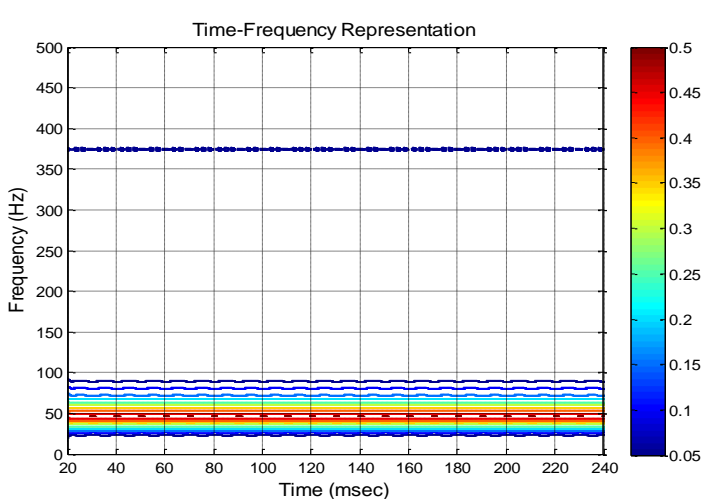

(b)
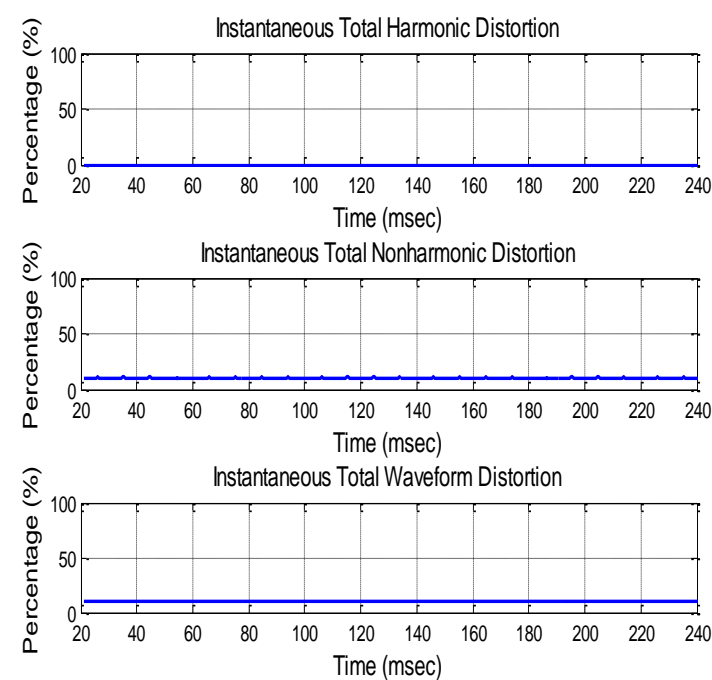

(d)

Figure 8. (a) Interharmonic signal in time domain, (b) Harmonic signal in TFR, (c) Instantaneous RMS voltage and RMS fundamental voltage, (d) Instantaneous total harmonic distortion, total nonharmonic distortion and total waveform distortion

\subsection{The Performance Analysis of the Time-frequency Distributions}

To identify the best method for harmonic signal analysis, TFDs are compared in terms of the accuracy, used memory size and computational complexity of the algorithm. 100 unique signals are generated and employed in the analysis.

\subsubsection{The Accuracy of the Analysis}

Harmonic signals are classified and the mean absolute percentage error (MAPE) of the signal characteristics is calculated as shown in Table 1. The table indicates that the ST gives an excellent accuracy of $V_{r m s}, T H D$ and TnHD. This is due to the method offers an excellent time resolution for high frequency and excellent frequency resolution for low frequency.

Table 1. MAPE of Simulation Results of the TFDs

\begin{tabular}{|c|c|c|c|}
\hline \multirow{2}{*}{ 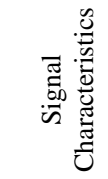 } & \multicolumn{3}{|c|}{ TFDs } \\
\hline & Spectrogram & Gabor Transform & S-transform \\
\hline Vrms $_{\text {ave }}$ & 0.1572 & 0.5293 & 0.0426 \\
\hline $\mathrm{THD}_{\text {ave }}$ & 0.1551 & 0.9967 & 0.0541 \\
\hline $\mathrm{TnHD}_{\mathrm{ave}}$ & 0.1595 & 0.9331 & 0.0533 \\
\hline
\end{tabular}


The tabulation of Table 1 is presented in the bar graph in order to have a good observation on MAPE value. The lower the MAPE value, the accurate the results are. Hence, the result plainly shows that the ST is the best method to measure the signal characteristics.

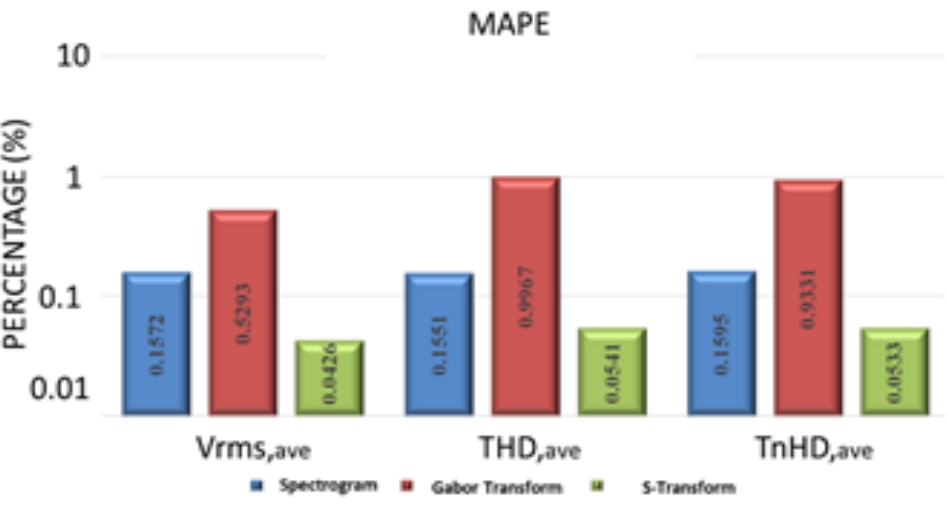

Figure 9. Average of MAPE for the TFDs

\subsubsection{The Computational Complexity of the Analysis}

The computational complexity of the analysis for each TFD is tabulated in Table 2. As demonstrates in the table, spectrogram, GT and ST contribute same computational ratio. This is because the windows length and a number of the signal are same for each TFD.

Table 2. Computation Complexity of the TFDs

\begin{tabular}{cccc}
\hline \multirow{2}{*}{ Signal } & \multicolumn{3}{c}{ TFDs } \\
\cline { 2 - 4 } & Spectrogram & Gabor Transform & S-transform \\
\hline Normal & $20,680,704$ & $1,041,408,000$ & $22,978,560$ \\
Harmonic & $20,680,704$ & $1,041,408,000$ & $22,978,560$ \\
Interharmonic & $20,680,704$ & $1,041,408,000$ & $22,978,560$ \\
\hline
\end{tabular}

The bar graph as presents in Figure 10, point out that spectrogram offers the lowest computational complexity, while GT is the highest. Hence, it is summarize that the spectrogram offers the fastest speed for harmonic signal analysis and then ST while GT is the slowest.

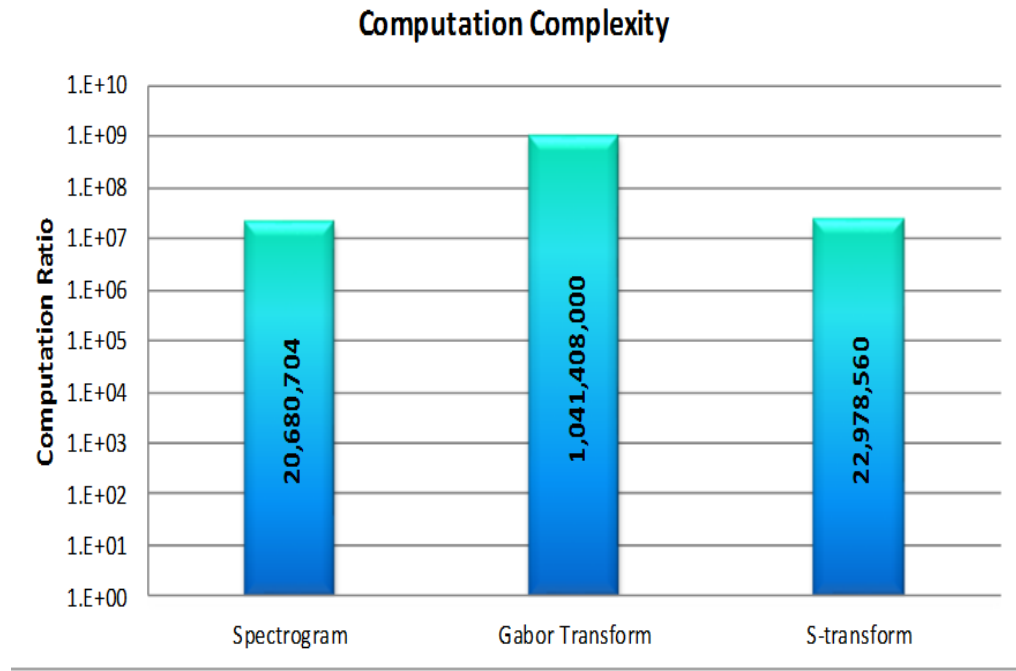

Figure 10. An average of computation complexity used for the TFDs 


\subsubsection{The Memory Size of Data Analysis}

Table 3 presents the average memory size used during the signal analysis for each TFD. Meanwhile, the graph as presented in Figure 11 show that the GT offers the lowest used memory size while spectrogram and ST utilized the biggest during the analysis. The memory size for spectrogram and ST are similar due to the same window size in the analysis.

Table 3. Used Memory Size of TFRs for the TFDs

\begin{tabular}{cccc}
\hline \multirow{2}{*}{ Signal } & \multicolumn{3}{c}{ TFDs, (Mbyte) } \\
\cline { 2 - 4 } & Spectrogram & Gabor Transform & S-transform \\
\hline Normal & $2,297,856$ & $2,250,000$ & $2,297,856$ \\
Harmonic & $2,297,856$ & $2,250,000$ & $2,297,856$ \\
Interharmonic & $2,297,856$ & $2,250,000$ & $2,297,856$ \\
\hline
\end{tabular}

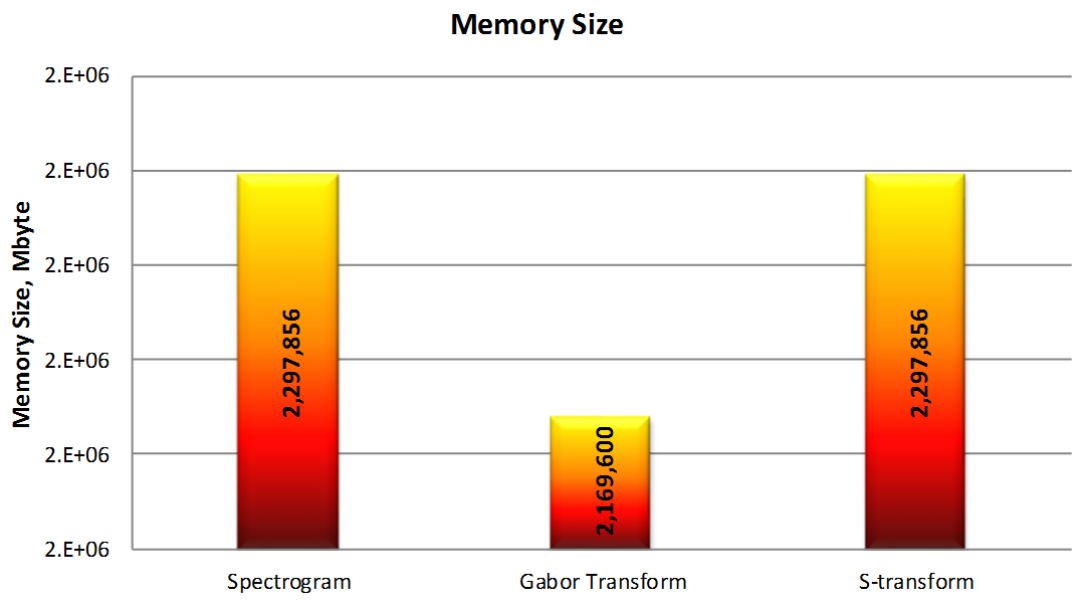

Figure 11. Average of memory size used for the harmonic signal analysis

\subsubsection{The Best Time-frequency Distribution Technique}

The results of the accuracy, computational complexity and used memory size of are depict in Figure 12. The performance evaluation of the best TFD based on the highest priority of criteria which is an accuracy, followed by the computational complexity and memory size.

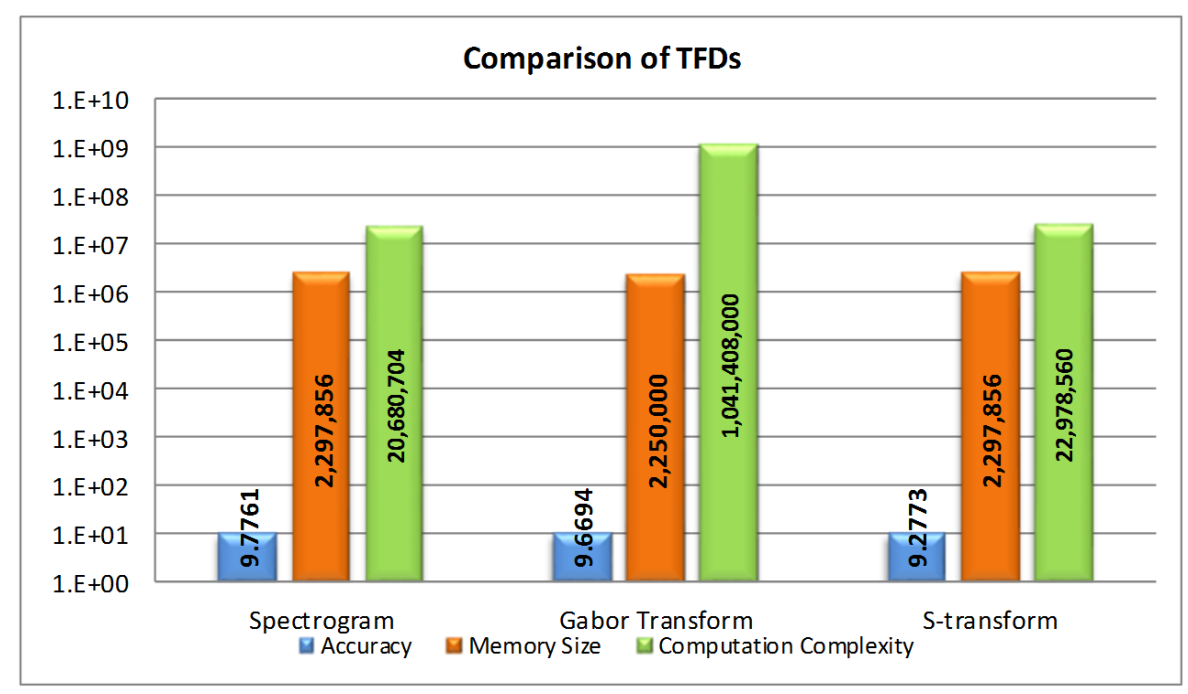

Figure 12. The performance comparison of TFDs 
As demonstrate in Figure 12, the spectrogram offers the lowest computational complexity. However, it used high memory size and provides the lowest accuracy. The poorest TFD is GT that request high computational complexity and offers low accuracy. Aimed at ST, it offers the highest accuracy, low memory size and additionally low computational complexity. Thus, the outcome, unmistakably, demonstrates that the ST is the best TFD for harmonic signal detection.

\subsubsection{The Classification of Harmonic Signal}

ST has been identified as the best TFD in this research for harmonic signals detection. The results of the signals classification using the ST are present in Table 4. The 100 unique signals with numerous characteristics were generated and classified. The classification results show that the ST provides $100 \%$ correct classification for all harmonic signals. From the outcomes, it can be inferred that ST is the best technique for harmonic signal detection and classification.

Table 4. Performance of Power Quality Signal Classification for S-transform

\begin{tabular}{ccc}
\hline \multirow{2}{*}{ Signal } & \multicolumn{2}{c}{ S-transform } \\
\cline { 3 - 3 } & Number of data sets & $\%$ Correct Classification \\
Harmonic & 100 & 100 \\
Interharmonic & 100 & 100 \\
Normal & 100 & 100 \\
\hline
\end{tabular}

\section{CONCLUSION}

The main concern of this paper is to evaluate and review the best TFD in harmonic signal detection and classification. The evaluation of the harmonic signal analysis using the TFDs actualized in timefrequency domain and compared in terms of accuracy, computational complexity and used memory size during the analysis. The performance of these methods are confirmed by detecting and classifying 100 unique signals with numerous characteristics of the harmonic signal. The outcomes demonstrate that ST is the best TFD with a criteria of the most accurate method, used low memory size and additionally low computational complexity.

\section{ACKNOWLEDGEMENTS}

This research is supported by Advanced Digital Signal Processing Laboratory (ADSP Lab). Special thanks also to the Center for Robotics and Industrial Automation (CeRIA) of UTeM, Faculty of Electrical Engineering and Engineering Technology of Universiti Teknikal Malaysia Melaka (UTeM), Ministry of Higher Education Malaysia (MOHE). The authors also gratefully acknowledge financial support from Ministry of Science, Technology and Innovation Malaysia (MOSTI) with a grant number of 06-01-14SF00119 L00025.

\section{REFERENCES}

[1] C. B. Khadse, M. A. Chaudhari, and V. B. Borghate, "Conjugate gradient back-propagation based artificial neural network for real-time power quality assessment," Int. J. Electr. Power Energy Syst., vol. 82, pp. 197-206, 2016.

[2] N. H. T. Huda and A. R. Abdullah, "Power quality signals detection using S-transform," Proc. 2013 IEEE 7th Int. Power Eng. Optim. Conf. PEOCO 2013, pp. 552-557, 2013.

[3] R. Kumar, B. Singh, and D. T. Shahani, "Symmetrical Components Based Modified Technique for Power Quality Disturbances Detection and Classification," IEEE Trans. Ind. Appl., vol. PP, no. 99, pp. 1-1, 2016.

[4] A. E. Lazzaretti, D. M. J. Tax, H. Vieira Neto, and V. H. Ferreira, "Novelty detection and multi-class classification in power distribution voltage waveforms," Expert Syst. Appl., vol. 45, pp. 322-330, 2016.

[5] N. H. T. H. Ahmad, N. A. Abidullah and N. H. Shamsudin, "Performance Evaluation of Real Power Quality Disturbances Analysis Using S-Transform,” Appl. Mech. Mater., vol. 752-753, pp. 1343-1348, 2015.

[6] M. Pujiantara, D. O. Anggriawan, A. Tjahjono, D. Permadi, A. Priyadi, and M. H. Purnomo, "A real-time current harmonic monitoring system based on stockwell transform method," Int. Rev. Electr. Eng., vol. 11, no. 2, pp. 193199, 2016.

[7] G. Z. Peng and S. A. Ghani,"A new vector draft method for harmonic source detection at point of common coupling," Proc. 2014 IEEE 8th Int. Power Eng. Optim. Conf. PEOCO 2014, no. March, pp. 110-114, 2014.

[8] S. a. Deokar and L. M. Waghmare, "Integrated DWT-FFT approach for detection and classification of power quality disturbances," Int. J. Electr. Power Energy Syst., vol. 61, pp. 594-605, 2014.

[9] T. Chen et al., "Harmonic detection method based on positive sequence extractor of fundamental current," in 2015 IEEE International Conference on Applied Superconductivity and Electromagnetic Devices, ASEMD 2015 Proceedings, 2016, pp. 242-243. 
[10] N. A. Abidullah, N. H. Shamsudin and N. H. H. Ahmad,"Performance Verification of Power Quality Signals Classification System," Appl. Mech. Mater., vol. 753, pp. 1158-1163, 2015.

[11] A. F. Noor Azam et al., "Current control of BLDC drives for EV application," Proc. 2013 IEEE 7th Int. Power Eng. Optim. Conf. PEOCO 2013, no. June, pp. 411-416, 2013.

[12] M. Z. R. Zuber Ahmadi, A. Jidin, K. B. Jaffar, M. N. Othman and R. N. P. Nagarajan "Minimization of torque ripple utilizing by 3-L CHMI in DTC," Proc. 2013 IEEE 7th Int. Power Eng. Optim. Conf. PEOCO 2013, no. June, pp. 636-640, 2013.

[13] Norddin, N.; Abidin, N.Q.Z.; Aman, A.; "Leakage current analysis on polymeric and non-polymeric insulating materials using time-frequency distribution," IEEE Int. Conf. Power Energy, no. December, pp. 2-5, 2012.

[14] N. A. Abidullah, A. R. Abdullah, N. H. Shamsudin, and N. H. T. H. Ahmad "Real-time power quality signals monitoring system," Proceeding - 2013 IEEE Student Conf. Res. Dev. SCOReD 2013, no. December, pp. 433-438, 2015.

[15] L. R. L. V. Raj, A. Jidin, K. Abdul Karim, T. Sutikno and R. Sundram, "Improved torque control performance of direct torque control for 5-phase induction machine," Int. J. Power Electron. Drive Syst., vol. 3, no. 4, pp. 391-399, 2013.

[16] C. H. Huang and C. H. Lin, "Multiple harmonic-source classification using a Self-Organization Feature Map network with voltage-current wavelet transformation patterns," Appl. Math. Model., vol. 39, no. 19, pp. 5849-5861, 2015.

[17] R. Kumar, B. Singh, D. T. Shahani, A. Chandra, and K. Al-Haddad, "Recognition of Power-Quality Disturbances Using S-Transform-Based ANN Classifier and Rule-Based Decision Tree,” IEEE Trans. Ind. Appl., vol. 51, no. 2, pp. 1249-1258, 2015.

[18] R. A. G. M. Gupta, R. Kumar, "Neural Network Based Indexing and Recognition of Power Quality Disturbances."

[19] N. Jrad, A. Kachenoura, I. Merlet, and F. Wendling, "Gabor transform for interictal high frequency oscillations classification," in 2015 International Conference on Advances in Biomedical Engineering, ICABME 2015, 2015, pp. $127-130$.

[20] N. Bahari, M. Manap and A. Jidin, "Short-Circuit Switches Fault Analysis of Voltage Source Inverter using Spectrogram," pp. 1808-1813, 2013.

[21] a. R. Abdullah, N. a. Abidullah, N. H. Shamsudin and N. H. H. Ahmad, "Power Quality Signals Classification System Using Time-Frequency Distribution," Appl. Mech. Mater., 2014.

[22] M. Manap, T. Sutikno, and M. F. Habban, "An Accurate Classification Method of Harmonic Signals in Power Distribution System by Utilising S-Transform," TELKOMNIKA (Telecommunication Comput. Electron. Control., vol. 15 , no. 1, 2017.

[23] M. B. Latran and A. Teke, "A novel wavelet transform based voltage sag/swell detection algorithm," Int. J. Electr. Power Energy Syst., vol. 71, pp. 131-139, 2015.

[24] D. D. Ferreira et al., "Method based on independent component analysis for harmonic extraction from power system signals," Electr. Power Syst. Res., vol. 119, pp. 19-24, 2015.

[25] S. Naderian and A. Salemnia, "Detection and classification of power-quality events using discrete Gabor transform and Support Vector Machine," in 6th Annual International Power Electronics, Drive Systems, and Technologies Conference, PEDSTC 2015, 2015, pp. 544-549.

[26] M. Valtierra-Rodriguez, R. De Jesus Romero-Troncoso, R. A. Osornio-Rios, and A. Garcia-Perez, "Detection and classification of single and combined power quality disturbances using neural networks," IEEE Trans. Ind. Electron., vol. 61, no. 5, pp. 2473-2482, 2014.

[27] N. A. Abidullah, G. Z. Peng and A. R. A. M., "A new two points method for identify dominant harmonic disturbance using frequency and phase spectrogram."

[28] A. A. Ahmad and A. Zuri, "Analysis and Classification of Airborne Radar Signal Types Using Time-Frequency Analysis," vol. 2014, no. September, pp. 23-25, 2014.

[29] T. Sutikno, and M. Manap, "A Utilisation of Improved Gabor Transform for Harmonic Signals Detection and Classification Analysis," Int. J., vol. 7, no. 1, pp. 21-28, 2017.

[30] M. R. Yusoff, T. Sutikno, and M. F. Habban, "An improved detection and classification technique of harmonic signals in power distribution by utilizing spectrogram," Int. J. Electr. Comput. Eng., vol. 7, no. 1, pp. 12-20, 2017.

[31] N. H. H., Abidullah, N. A, Abdullah, A. R., Zuri_Sha'ameri, A., Shamsudin, N.H., Ahmad, "Real-Time Power Quality Disturbances Detection and Classification System," World Appl. Sci. J., vol. 32, no. 8, pp. 1637-1651, 2014.

[32] N. H. T. Ahmad and N. A. Abidullah, "Analysis of Power Quality Disturbances Using Spectrogram and Stransform," Int. Rev. Electr. Eng., vol. 3, no. June, pp. 611-619, 2014.

\section{BIOGRAPHIES OF AUTHORS}

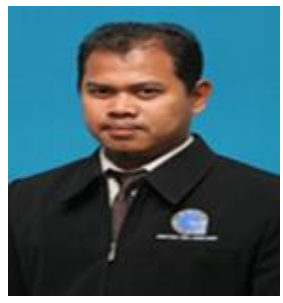

Mohd Hatta Jopri was born in Johor, Malaysia on 1978. He received his B.Sc from Universiti Teknologi Malaysia in 2000 and Msc. in Electrical Power Engineering from RheinischWestfälische Technische Hochschule Aachen (RWTH), Germany in 2011. Since 2005, he has been an academia staff in the Universiti Teknikal Malaysia Melaka (UTeM) and currently he is pursuing his $\mathrm{PhD}$ in the area of power quality. 

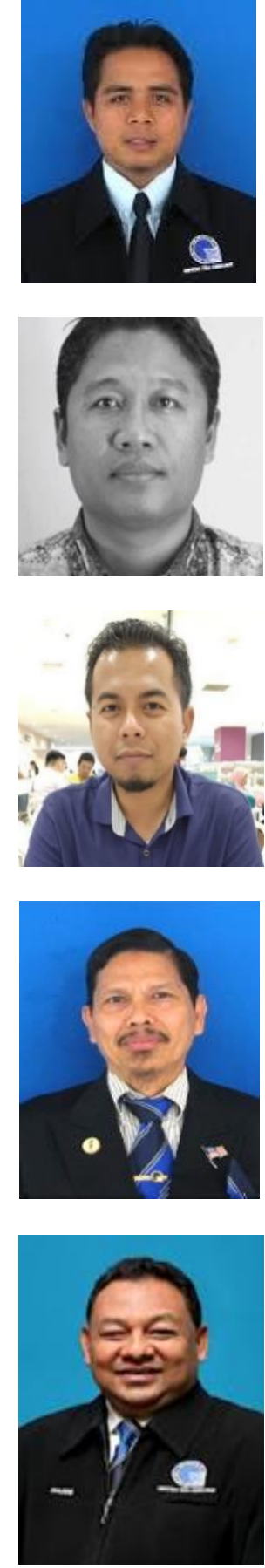

Mohd Rahimi bin Yusoff was born in Kelantan, Malaysia on 1967. He received his M.Sc. in Electrical Engineering from University of Nottingham, England in 1992 and B.Eng. in Electrical \& Electronics from University of Wales, Swansea, UK in 1990. Since 2010, he has been an academia staff in Universiti Teknikal Malaysia Melaka (UTeM) and currently holding the post as Dean of Faculty of Engineering Technology. His research interests are power quality, signal processing, and DSP application. 